\title{
O ensino sobre etnicidade nas escolas de uma cidade no estado da Paraíba
}

\author{
Teaching on ethnicity in schools of one city of Paraíba
}

\author{
Ana Cristina Silva Daxenberger ${ }^{1 *}$, Monique Gonçalves Alves², Rosivaldo Gomes de Sá \\ Sobrinho $^{1}$, Risoneide Borges da Silva Costa ${ }^{1}$
}

\begin{abstract}
RESUMO
Para validar e reconhecer as contribuições da população negra ao desenvolvimento nacional, a Lei 10.639/03 instituiu a obrigatoriedade do ensino da História da África e suas contribuições à cultura brasileira, nos currículos escolares, o que pode favorecer no fortalecimento da construção de uma escola cidadã. Considerando isto, esse trabalho tevecomo objetivo avaliar o processo de implementação da Lei 10.639/03, nas escolas públicas de um munícipio do interior, no estado da Paraíba. O trabalho foi desenvolvido pelo Prolicen (programa de licenciatura), utilizando-se de questionários semiestruturados e observação do cotidiano escolar e de aulas; sendo participantes 35 professores do ensino fundamental. Foi constatado que os professores acreditam que a inclusão social dentro do ambiente escolar é necessária, entretanto não trabalham efetivamente a educação étnico-racial. Isto se deve pela falta de formação docente, o que gera despreparo de como inserir tal temática de forma interdisciplinar e efetiva nas aulas, reproduzindo assim o preconceito e não permitindo que os educandos sintam orgulho da cultura afrobrasileira e nem tenham o sentimento de reconhecimento étnico.
\end{abstract}

Palavras-chave: Lei 10.639/03; Etnicidade; Formação docente.

\begin{abstract}
In order to validate and recognize the contributions of the black population to national development, Law 10.639/03 established the obligation to teach the History of Africa and its contributions to culture, which may favor the strengthening of the construction of a public school. Considering this, the research's aims were to evaluate how is the process of implementation of Law 10.639/03, in the public schools of the one city of Paraíba. The research was developed by Prolicen (teacher graduation program), was used semistructured questionnaires and daily school observation and lessons; being 35 primary school teachers. It was found that teachers believe that social inclusion within the school environment is necessary, but they do not actually work ethno-racial education. This is due to the lack of teacher training, which generates unpreparedness of how to insert such subject in an interdisciplinary and effective way in the classes, thus reproducing the prejudice and not allowing the students to feel proud of the Afro-Brazilian culture and neither have the feeling of recognition ethnic.
\end{abstract}

Keywords:Law 10.639/03; Ethnicity; Teacher training.

${ }^{1}$ Universidade Federal da Paraíba (UFPB).

*E-mail: ana.daxenberger@academico.ufpb.br

${ }^{2}$ Universidade de São Paulo (USP) 


\section{INTRODUÇÃO}

Segundo Costa e Dutra (2009), descolonizar o saber é o primeiro passo na luta contra o preconceito racial logo que é, no espaço escolar, que acontece boa parte da formação pessoal dos indivíduos. Sendo assim, a escola é um ambiente fundamental para a superação do racismo e desigualdades raciais. Porém, embora seja a escola o ambiente no qual deveria ser debatido e desconstruído tais questões, Domingues (2005, p. 172), afirma que o que ocorre "[...] é um racismo dissimulado, mascarado, velado, porém extremamente eficiente".

Paulo Freire $(1996,1997)$, em suas obras, apresenta a denúncia ao que ele intitula como educação bancária no que se diz respeito aos saberes e práticas curriculares que procedem de uma tradição eurocêntrica, sendo esta denúncia um ponto matriz para a construção de um currículo crítico e emancipatório. Quijano (2005) discute o eurocentrismo, mais precisamente o etnocentrismo, ao explicar que ele surgiu mediante o êxito da Europa Ocidental em transformarse no centro do moderno sistema-mundo:

A associação entre ambos os fenômenos, o etnocentrismo colonial e a classificação racial universal, ajudam a explicar por que os europeus foram levados a sentir-se não só superiores a todos os demais povos do mundo, mas, além disso, naturalmente superiores (Quijano, 2005, p. 6).

À vista disso, a sociedade brasileira é marcada pela diversidade de etnias e culturas que ao longo dos anos da história da educação brasileira não obtiveram o reconhecimento e à valorização, centralizando-se a educação escolar em um modelo de educação eurocêntrico e ocidentalizado. Reconhecer as diferenças implica romper com preconceitos, superar as velhas opiniões formadas sem reflexão, sem o menor contato com a realidade do outro (GOMES, 2003).

Para isso arroga-se na Constituição Federal Brasileira, de 1998, tal como também preconizam as Leis 10.639/03 e 11.645/08, as quais estabelecem a inclusão do ensino da História e da Cultura Africana e Afrobrasileira nas escolas de ensino nível fundamental e médio, no Brasil, tornando-o obrigatório em todo o currículo. Como evidencia Videira (2008, p. 224) sobre tais exigências legais no âmbito escolar:

A adoção desse novo paradigma cria condições para que os estudantes negros e negras não sejam rejeitados por causa da cor da sua pele, menosprezados por seus antepassados terem sido explorados como escravos, não sejam desencorajados de prosseguir seus estudos, inclusive estudar questões que dizem respeito à comunidade negra.

Assim sendo, concordamos com a proposição apresentada por Candau (2007), na qual ela afirma que: 
A igualdade que queremos construir, assume a promoção dos direitos básicos de todas as pessoas. No entanto, esses todos não são padronizados, não são os "mesmos". Têm que ter suas diferenças reconhecidas como elementos da construção da igualdade... Hoje não se pode mais pensar na afirmação dos Direitos Humanos a partir de uma concepção de igualdade que não incorpore o tema do reconhecimento das diferenças, o que supõe lutar contra todas as formas de preconceito e discriminação (p. 400).

Consequentemente, assim como Gomes (2003) pergunta: qual é o trato pedagógico que a escola tem dado as diferenças? Sabendo que os/as educadores/as são também profissionais da cultura e não de um padrão único de aluno, de currículo, de conteúdo, de práticas pedagógicas e de atividades escolares, nos conduz a um repensar do papel do/a professor/a. Sendo assim, o objetivo geral da pesquisa foi avaliar como estava se constituindo o processo de implementação da Lei Federal de n ${ }^{\circ}$ 10.639/03, nas escolas do sistema público municipal e/ou estadual de educação, especificamente, no ensino fundamental I; no entorno do campus II, da Universidade Federal da Paraíba (UFPB), relacionado, especificamente sobre o ensino da História da África e cultura Afro-brasileira.

Vale ainda ressaltar que as atividades desenvolvidas e explanadas neste artigo, fizeram parte das ações do Projeto de Licenciatura (Prolicen), vinculados a Pró-reitora de Graduação, da Universidade Federal da Paraíba (UFPB), com uma bolsista na área de Licenciatura em Ciências Biológicas, durante o ano civil de 2018.

\section{METODOLOGIA}

A pesquisa foi realizada em um município do interior no estado da Paraíba, para a qual tivemos sete escolas do ensino fundamental I que se localizam entre a zona urbana e seus distritos rurais. A abordagem de pesquisa é de cunho qualitativo, para a qual Bogdan e Biklen (1994, p.16) explicam: "Ainda que os indivíduos que fazem investigação qualitativa possam a vir a selecionar questões específicas à medida que recolhem os dados, a abordagem a investigação não é feita com o objetivo de responder a questões prévias ou testar hipóteses".

Para a coleta de dados, inicialmente, o instrumento metodológico utilizado foi um questionário semiestruturado, constituído por dezesseis questões, dentre elas quatro fechadas e as demais abertas. Para que fosse preservada a identidade dos 35 professores que participaram deste trabalho, suas falas foram registradas pelo código alfanumérico P1, P2, P3 e assim por diante.

Posterior à coleta de dados mediante questionário, foi feito uma observação in lócus em uma das escolas que já havia participado da primeira etapa, para investigarmos de que maneira a Lei 10.639/03 estava sendo desenvolvida no currículo e no cotidiano escolar, e identificar ações que revelassem o cumprimento, ou não, do que é exigido por lei. Foi observado o espaço físico 
escolar com objetivo de identificar materiais e/ou instrumentos relacionados à história e cultura afro-brasileira e africana. A coleta de dados, por meio da observação, ocorreu em um período de três semanas, com a observaçao das práticas de quatro professores, nas áreas de história, artes, geografia e português. A observação levou em consideração como o professor ministrava as aulas, se o tema etnicidade era introduzido dentro do conteúdo de cada área especifica e como os profissionais lidavam com casos de desvalorização da cultura, arte ou qualquer outro tipo de discriminação étnico racial que ocorresse em sala de aula. Vale ressaltar que a escolha da escola para observação, se deu por ser ela inserida em um distrito na zona rural, com público oriundo na maioria de grupos étnicos com histórico de famílias que, em sua ancestralidade, sofreram a escravização, recebendo alunos oriundos de uma comunidade quilombola no distrito em que ela está inserida.

\section{RESULTADOS E DISCUSSÕES}

Fundamentados nos aspectos legais (BRASIL, 1988; BRASIL, 1996; BRASIL, 2003, 2004) e nos princípios de reconhecimento de identidade étnico-racial (Quijano, 2005; Domingues, 2005; Gomes, 2003; Candau, 2007; Daxenberger e Sá Sobrinho, 2013; Daxenberger, Sá Sobrinho \& Silva, 2014; Costa \& Dutra, 2009) analisamos os questionários aplicados. Foi possível perceber que todos os professores acreditam que a inclusão social dentro do ambiente escolar é necessária e importante. Os dados apontam como justificativa as temáticas de respeito à diversidade para que assim haja uma educação de qualidade e garantias constitucionais quanto à igualdade. Entretanto, 14 professores admitem que, dentro do ambiente escolar vivenciado, não seja algo trabalhado diretamente pela escola, denunciando a falta de medidas tomada pela gestão para haver uma capacitação ou não se incluindo como parte integrante da responsabilidade de desenvolver tais competências com os educandos. O que se percebe é que esse trabalho é considerado como uma obrigação exclusiva de iniciativa da gestão escolar, não sendo os professores, também, sujeitos integrantes e competentes para contribuírem com a aproximação e valorização dos valores civilizatórios afro-brasileiros. Assim alguns dos pesquisados se expressam:

Necessária para um país com um altíssimo grau de miscigenação e repetidas histórias de fracasso escolar de crianças e adolescentes negros. (P3)

Interessante, melhor seria se a escola nos ajudassem (sic) em relação de como trabalhar melhor com a inclusão. (P10)

Ainda acho muito superficial, pois precisa de um apoio por parte dos órgãos competentes. (P17) 
Em contrapartida outros participantes apresentam a necessidade em terem formação continuada, admitindo que precisem de um maior conhecimento de como lidar com determinadas situações de reconhecimento identidário e se enquadrando como ser ativo de mudança que soma na construção do conhecimento e dos valores dos educandos:

Eu acho que é importante todos serem tratados com igualdade, porém é necessário uma preparação para lidar com certos casos (P5).

Necessária desde que a escola ofereça as condições necessárias, como formação para abordar o tema (P11).

A inclusão no ambiente escolar não é fácil, portanto temos dificuldades de ministrar aulas sobre, pois cada ser (aluno e família) em de famílias diferentes, com pensamentos diferentes, e para que seja de ato aceito, levamos muito tempo e talvez nem conseguíssemos. Não depende só dos professores, mas de toda uma equipe (P2).

Mesmo observando que os professores falaram muito sobre a falta de capacitação e de estímulo da gestão escolar, foi constatado que $45 \%$ dos entrevistados admitiram que o estímulo aos professores pela gestão e/ou sistema de ensino (Secretarias de Educação Municipal e Estadual) para ensinar educação étnico racial variou entre os indicadores $33 \%$ afirmaram ser pouco estimulados e $41 \%$ afirmaram ser razoavelmente estimulados. Os demais $55 \%$ dos participantes, responderam que o estímulo é médio (18\%), bastante (4\%) e muito (4\%).

Setenta por cento dos professores disseram que trabalham conforme a Lei 10.639/03. Alguns afirmaram: "Além de fazer parte do currículo, faz parte da nossa história" (P5); "Não podemos abrir mão de conhecer e valorizar a nossa formação cultural, étnica e social" (P2); "Trabalho sempre quando pode ser contextualizado (P12)".

É importante perceber que tais professores entendem que trabalhando com ênfase nas relações relaçõesétnico-raciaisé possibilitado aos alunos o orgulho por sua cultura que, por sua vez, desencadeia em outros processos como a afirmação da autoestima, no qual é reconhecido em um grupo que todos são diferentes, mas não desiguais. Essa desconstrução do imaginário racista que é resultado dos processos de dominação eurocêntrica é de responsabilidade dos professores, bem como de todas as instituições de ensino e os que a compõe.

As Diretrizes Curriculares para a Educação das Relações Étnico-Raciais e para o Ensino de História e Cultura Afro-Brasileira e Africana (2004) deixam explícito tal importância, quando tomadas por bases filosófica e pedagógica os seguintes princípios: a) açõeseducativas de combate ao racismo e a discriminações, e estimular estratégias de ensino e tarefas mediante as experiências de vida dos alunos; b) valorizando as aprendizagens e as relações diversas entre negros, indígenas e brancos no conjunto da sociedade, cabendo ao corpo escolar providencias que permitam que professores e alunos enfrentem e superem conflitos sobre as relações étnico- 
raciais; c) valorizando os contrastes das diferenças partindo do patrimônio cultural afrobrasileiro, buscando difundi-lo, preservá-lo e construir significações positivas que promovam respeito a diversidade cultural e histórica.

Porém, muitos outros professores não explicam de que maneira trabalham, todavia outros como o P7 e o P9, respectivamente, disseram que "Trabalho porque vem no livro didático"; e "Nós trabalhamos sobre a África porque tem o conteúdo no nosso livro de história". O que podemos afirmar é que nem sempre os professores reconhecem os princípios que estão das DCN sobre Educação das Relações Étnico-raciais (2004); e só desenvolve a temática porque já está inserida nos livros didáticos, os quais são utilizados sem uma reflexão crítica.

É preocupante que os participantes não veem a necessidade da inserção desse tema no campo da educação escolar. O interessante é perceber que os que possuem esta visão (de não importância sobre os aspectos exigidos pela Lei 10.639/2003); bem como outros entrevistados que deram respostas semelhantes, são os mesmos que não respondem se o estudo da África e sua cultura favorece à construção de educação antirracista. Eles dizem que não possuem conhecimento sobre a lei supracitada; não acham importante os cursos de formação continuada sobre a temática ou não respondem se são capacitados para desenvolver as temáticas propostas por tal lei. Tais posicionamentos estão em acordo com o que Domingues (2005, p.172) afirma: "[...] o progresso educacional do negro brasileiro é inferior ao do negro sul-africano da época do apartheid, e dos negros dos Estados Unidos da época da segregação racial. Nesses países, havia maior número de médicos, engenheiros e advogados negros do que aqui." Muitos profissionais da educação não reconhecem à importância e o fortalecimento da identidade étnica do povo brasileiro.

É preciso que ações de combate ao preconceito racial sejam efetivadas através de ações afirmativas e de políticas públicas que corrijam as distorções históricas que atinge a população brasileira, contribuindo para que história seja contada a partir de outra perspectiva. A reconstrução da história buscando o reconhecimento do povo escravizado e que contribuiu na formação social, econômica e cultural desta Nação, deve absorver a ideia que, hoje, o que é de origem negra compõe a origem brasileira. Em outras palavras, a história da população negra, no Brasil, é a historia dos brasileiros, para que assim não seja reproduzido na escola, uma versão reducionista sobre a população negra e se mantenha o mito da democracia racial brasileira.

Logo, constatamos que ocorre uma contradição que pode ser observado nas falas dos participantes, mediante análise dos dados sobre a introdução da temática etnicidade no currículo escolar e sobre a periodicidade dos trabalhos desenvolvidos pelos docentes. Apesar de nenhum dos professores considerarem que a temática é muito abordada no cotidiano escolar, $4 \%$ 
classificou como bastante abordada, 26\% medianamente, $29 \%$ de maneira razoável e $41 \%$ considerou como pouco abordado.

A ênfase é feita porque se somente $41 \%$ dos participantes assumem que é pouco abordado quando comparado também com a frequência da abodagem, temos os seguintes dados: 44\% indicou que é feito no mês de Maio, especificamente, no Dia da Abolição da Escravatura e 49\% em Novembro, no Dia da Consciência Negra, apenas 5\% declarou que há uma abordagem semanalmente e $2 \%$ mensalmente.

Esses dados nos indicam um índice preocupante sobre o entendimento do quanto é necessário abordar as questões raciais dentro da perspectiva analisada na visão dos participantes. Afinal, podemos afirmar que, se o tema só é abordado em datas específicas ele não tem efetividade de prática docente, no cotidiano escolar, para a construção de prática de fortalecimento identidário e nem tampouco, atendem as demandas legais. Para além da legalidade, refletimos sobre a falta de materialização de ações que reconheçam o público atendido pelas escolas participantes. A grande maioria da população escolar matriculada no município apresenta laços com a história da colonização portuguesa e à exploração da mão de obra escravizada, considerando que o município teve grande importância social, política e econômica estadual no período colonial e de exploração de mão de obra escrava na produção de cana-de-açúcar.

Provavelmente, devido a ausência de uma educação antirracista e até mesmo um precário ensino de história e cultura afro-brasileira e africana é que $30 \%$ dos entrevistados relataram a falta de interesse dos alunos sobre a temática. Esse dado ratifica a falta de compreensão sobre a importância da educação acerca das relações étnico-raciais e, ainda, podemos hipotetizar que a falta de interesse dos educandos pode ser por não se reconhecerem como afro-brasileiros. Mediante isso, cabe reforçar que assim como dito por Gomes (2007, p. 102), as escolas devem "[...] inserir a questão racial no seu projeto político pedagógico, tomá-la como eixo das práticas pedagógicas e articulá-las nas discussões que permeiam o currículo escolar" indo além de uma ação eventual. Isso requer incorporação: “[...] nas metas educacionais do país, no Plano Nacional de Educação, no Plano de Desenvolvimento da Escola, nos planos estaduais e municipais, na gestão da escola e nas práticas pedagógicas e curriculares de forma mais contundente" (GOMES, 2009, p.41).

Ainda assim, se faz necessário repensar a estrutura escolar, as lacunas na formação dos professores e reconhecer que estes não são alvos da preocupação dos que formulam as políticas educacionais brasileiras. É importante que estes profissionais saibam como dar sentido ao conhecimento que lhes é adquirido e exigido por uma sociedade mais democrática. 
Tal afirmativa é corroborada quando $63 \%$ dos entrevistados não se sentem capazes de desenvolver as temáticas propostas pela lei 10.639/03:

Há falta de planejamento e formação direcionado a temática. (P24)

Preciso participar de formações em busca de melhor preparação. (P8)

Não tive preparação para tal. (P19)

Porque infelizmente o professor não passa por formações aprofundadas com esta temática, mas o pouco que dominamos, podemos contribuir com os alunos. (P 25)

Do mesmo modo que quando é perguntado sobre os materiais didáticos utilizados, 7 professores entrevistados se limitam a apresentar às experiências que tratam sobre o racismo reduzindo-o como um "problema dos negros" e não relacionado ao legado do modelo escravocrata e suas marcas deixadas na estrutura social. Podemos apontar como aspectos de fortalecimento desta desigualdade étnico-social presente desde pequenos estigmas presentes com a valorização de uma estética "branca" até a intolerância religiosa, com a sobreposição do catolicismo e outras religiões cristãs em detrimento as religiões de matrizes africanas. Estas marcas não só desvalorizam a cultura negra como podem favorecer a violência simbólica.

No que se refere às temáticas de interesse para estudos, foi percebido que religiosidade, cultura, heróis negros, história sobre os reinos africanos, dança e literatura são as que menos despertam interesses de serem estudadas pelos professores. Em contrapartida, as áreas de maior interesse são educação antirracista, racismo e preconceito, o que novamente, mostra-se contraditório, pois como promover uma educação antirracista e de fortalecimento da identidade étnico-racial se não sabemos de onde viemos? As contribuições sociais e culturais provenientes da cultura africana que permanecem diluídas no nosso dia a dia? Sem sabermos como nos constituímos e como nos formamos brasileiros na contemporaneidade? Tais questionamentos nos remetem à possibilidade de outras reflexões para além desta pesquisa.

O Brasil é um país oficialmente laico, contudo essa laicidade ainda não é observada em todos os segmentos e espaços sociais do Estado. Na prática é perceptível que alguns segmentos religiosos se sobrepõem a outros que são estigmatizados e sofrem preconceitos mediante um conhecimento popular distorcido, sobretudo, em relação às religiões afro-brasileiras, como o candomblé, a jurema e a umbanda. Estas foram e, ainda, são as que mais sofrem tais distorções ao longo da história nacional, por falta de conhecimento da população sobre elas ou por préconceito (SILVEIRA, 2013). Consequentemente, uma parte da população brasileira não se decla como adeptas a estas religiões com medo de um pré-conceito, intolerância religiosa ou por não quererem se submeter às situações de questionamentos em ambientes públicos que podem interferir diretamente em outros aspectos da vida, dentre eles, a escola. 
Contrariamente a esta situação, vemos símbolos do cristianismo exposto em vários locais. Ela, ainda é identificada como uma religião do "bem", e sendo, a única erroneamente, valorizada dentro do âmbito escolar em muitas escolas, não só como conhecimento repassado pelos professores, mas também por meio de imagens religiosas entre outros discursos depreciativos ocultos nas vozes de alguns agentes sociais da educação que firmam a ideia de que esta religião é a certa e as demais provavelmente não, ocasionando uma "proibição velada" e uma violação à autoidentificação dos próprios educandos sobre seus princípios religiosos e/ou de suas famílias.

Vale ressaltar que o Brasil é signatário da Declaração de Durban, (2001) na qual também trata sobre a liberdade de escolha religiosa. Assim está expressa:

Art. 59. Reconhecemos com profunda preocupação a intolerância religiosa contra algumas comunidades religiosas, bem como a emergência de atos hostis e de violência contra tais comunidades por causa de suas crenças religiosas e de sua origem racial ou étnica em várias partes do mundo, o que limita, particularmente, o seu direito de praticar seu credo livremente (DECLARAÇÃO DE DURBAN, UNESCO, 2001, p.14).

Da mesma forma que acontece com a religião, quando um povo não reconhece pessoas que são semelhantes como exemplos de identidade de sucesso e possíveis de valorização, a sociedade perde com o não reconhecimento de sua própria identidade. Em muitos casos durante toda uma vida escolar são estudados diversos "heróis" que contribuíram de algum modo para a história tanto brasileira e mundial. Todavia, há ainda um preconceito em reconhecer a população negra como membros sociais que trouxeram grandes avanços tecnológicos e contribuições significativas para a sociedade. (Cunha, s/d)

Equitativamente, sendo a cultura "[...] o conjunto de traços distintivos espirituais e materiais, intelectuais e afetivos que caracterizam uma sociedade ou um grupo social ..." (UNESCO, 2002, s/p), para que haja de fato um conhecimento que venha combater o racismo e o preconceito de maneira efetiva, é necessário que os professores conheçam profundamente mais a respeito da cultura afro-brasileira.

No que tange as observações in lócus, foi observado que os professores possuem um conhecimento restrito quanto aos pressupostos da Lei 10.639/03. Entretanto é identificável, ao se manter diálogo com professores participantes, uma preocupação da gestão e dos professores na inserção da educação para as relações étnico raciais, em sala de aula. Isto ocorre, em especial, com os que ensinam história e geografia, entretanto em muitas oportunidades, durantes as aulas, observamos que eles poderiam ter feito uma relação entre temas que estavam sendo abordados correlacionando-os com a realidade racial brasileira e não o fizeram. É interessante que nesses momentos, em sua maioria os alunos estavam dispersos sobre o assunto, caso que 
talvez não acontecesse se fossem inseridos dentro da própria realidade de debate. Concordando com Careno (2004) sobre esta problemática: ausência da relação do conteúdo escolar com a realidade dos estudantes, podemos apontar que

\begin{abstract}
Apenas a lei não basta para ocorrer, de fato, uma mudança curricular em nossas escolas, na formação e na prática dos profissionais da educação. ... parece que estamos lecionando em algum país nórdico tal é a ausência da abordagem relative [...] à questão negra na História Brasileira. [...] some-se ao alegado desconhecimento da lei o fato de que a nossa educação exclui sistematicamente a dimensão étnica do trabalho curricular. (Careno, 2004, p.3)
\end{abstract}

Dentre os assuntos estudados na área de história, a Segunda Guerra Mundial foi o que permitiria maiores correlações sobre a temática exigida na Lei 10.630/2003. O holocausto, a intolerância religiosa, cultural, racial poderia ter sido bastante trabalhada e trazida para a realidade dos alunos de modo que entendessem o que acontecia naquela época, percebendo-se como seres sociais críticos que hoje constantemente passam, presenciam ou reproduzem atos preconceituosos e intolerantes não na mesma dimensão, mas com impactos tão prejudiciais para a sociedade e a vida. Porém, é provável que tal tema não tenha sido abordado paralelamente devido o professor ter uma falta de conhecimento maior, preparação ou não saber como inseri-lo no assunto ministrado.

Sendo o educador um sujeito, que, conjuntamente com outros sujeitos, constrói, em sua prática, um projeto histórico de desenvolvimento do povo, que se dá por meio da execução de um projeto político pedagógico (Luckesi, 1982), como Morreto (2007) diz, é de grande importância o ato de planejar e organizar, uma vez que facilita tanto para o professor quanto para o educandos as ideias, informações, conhecimentos e também o tempo disponível.

O que podemos constatar por meio das observações, é que realmente a educação para as relações étnico-raciais é centrada nos dias de comemoração nacional relacionadas à Abolição da Escravatura e ao Dia de Consciência Negra, pois não constatamos nada relacionado como prática constate e efetiva para a construção do fortalecimento de identidade étnico-racial. Constatamos também indícios que não existe a valorização dos aspectos religiosos de matrizes africanas como já apontado nas reflexões anteriores e que somente há a utilização do livro didático como material de apoio para a introdução de novos conhecimentos.

\title{
CONSIDERAÇÕES FINAIS
}

De modo geral os professores reconhecem a necessidade de tratar sobre a temática nas instituições de ensino, mas há uma deficiência no conhecimento sobre a Lei 10.639/03, bem como de que forma aplicá-la em sala de aula, com êxito e de maneira crítica, tendo em vista que só inserem em sala de aula o que está inserido previamente na programação didática prevista 
nos livros didáticos, deixando para discutir sobre tal temática em datas que já estão previamente programadas.

Como discutido acima, reforça-se a ideia da necessidade de formação docente, identificando-se o desconhecimento e despreparo teórico-prático dos professores a cerca do tema, bem como sobre os princípios legais, no qual os professores compreendem que é o estudo de uma cultura qualquer sem necessidade de uma abordagem interdisciplinar, contextualizada, com fatos contemporâneos correlacionados aos aspectos históricos brasileiros. Para isso é importante o envolvimento de todos para a construção de projeto pedagógico que atenda as necessidades a cerca do combate ao preconceito racial, lutando por uma educação não excludente e de valorização multicultural.

Pelos dados apontados na pesquisa, podemos ainda alertar para a necessidade de formação docente a todos os profissionais de educação dos sistemas; a elaboração de um projeto político pedagógico alicerçado em base de reconhecimento da diversidade humana e do povo brasileiro; a construção de práticas educativas reflexivas para a construção do fortalecimento da identidade dos educandos, bem como dos educadores que em muitas vezes, não se enxergam como não só um instrumento de ação para mudança, mas também como sujeito a ser transformado dentro de uma educação antiracista e de reconhecimento socio-cultural de matriz africana; além de proposição de socialização de práticas exitosas para a consolidação de uma educação antirracista e, por fim, a elaboração de um sistema de monitoramento sobre a materialização da Lei 10.639/03.

\section{REFERÊNCIAS}

BOGDAN, R.; BIKLEN, S. Investigação qualitativa em educação: uma introdução à teoria e aos métodos. Cidade do Porto: Porto, 1994.

\section{BRASIL. Diretrizes Curriculares para a Educação das Relações Étnico -Raciais e para o}

Ensino de História e Cultura Afro-Brasileira e Africana. Brasília: DF, Outubro, 2004.

BRASIL. Constituição Federal. Constituição da República Federativa do Brasil. Brasília, DF, Senado Federal, 1988.

BRASIL. Lei $\mathbf{n}^{\circ}$ 9.394, de 20 de dezembro de 2006. Estabelece as diretrizes e bases da educação nacional. . Diário Oficial [da] República Federativa do Brasil. Brasília, DF, 1996. 
BRASIL. LEI No 10.639, de 9 de janeiro de 2003. Altera a Lei $n^{\circ} 9.394$, de 20 de dezembro de 1996, que estabelece as diretrizes e bases da educação nacional, para incluir no currículo oficial da Rede de Ensino a obrigatoriedade da temática "História e Cultura Afro-Brasileira". Brasília, DF, 2003.

BRASIL. Diretrizes Nacionais Curriculares para a Educação das Relações Étnico-raciais. Diário Oficial da União, de 22 de junho, Brasília, DF, 2004.

CANDAU, V. M. Educação em direitos humanos: desafios atuais. In. SILVEIRA, R. M. G. et al. Educação em direitos humanos: fundamentos teóricos-metodológicos. João Pessoa: Editora Universitária, 2007.

CARENO, MARY FRANCISCA DO. A Lei 10639, a diversidade cultural e racial e as práticas escolares. Jornal Bolando Aula de História, (46), p. 3, set. 2004.

CARENO, Mary Francisca do. Vale do Ribeira: a voz e a vez das comunidades negras. São Paulo: Arte \& Ciencia:1997, 160p.

COSTA, Raphael Luiz Silva; DUTRA, Diego França. A Lei 10639/2003 e o ensino de Geografia: representação dos nefros e África nos livros didáticos. $10^{\circ}$ ENCONTRO NACIONAL DE PRATICA DE ENSINO DE GEOGRAFIA. Porto Alegre, 2009. Disponível em: 〈http://www.agb.org.br/XENPEG/artigos/GT/GT3/tc3\%20(12).pdf> . acesso em: 15 de agosto de 2018.

CUNHA, Lázaro. As contribuições dos povos africanos para o conhecimento científico tecnológico e universal. s/d. Disponível em: http://www.acaoeducativa.org.br/fdh/wpcontent/uploads/2012/11/contribuicao-povos-africanos.pdfAcesso em 15 de novembro de 2015.

DAXENBERGER, Ana Cristina Silva e SÁ SOBRINHO, Rosivaldo Gomes. A diversidade com estudos dos princípios étnicos. Editora UFPB: João Pessoa, 2013.

DAXENBERGER, Ana Cristina Silva e SÁ SOBRINHO, Rosivaldo Gomes, Silva, Magna Lúcia. Educação e etnicidade: Diálogos Interdisciplinares. Editora UFPB: João Pessoa, 2014.

DOMINGUES, Petrônio. Ações afirmativas para negros no Brasil: o inicio de uma reparação histórica, (29), 172. São Paulo: Autores Associados, 2005.

FREIRE, Paulo. Pedagogia do Oprimido. São Paulo: Paz e Terra. 57-76. 1996. 2. A concepção bancária da educação como instrumento da opressão. 
FREIRE, Paulo. Pedagogia da Autonomia: saberes necessários à educação. São Paulo: Paz e Terra, 1997.

GOMES, Nilma Lino. Educação e diversidade étnico-cultural. RAMOS, MN; ADÃO, JM; BARROS, GMN (Coords.). Diversidade na educação: reflexões e experiências. Brasília: Secretaria de Educação Média e Tecnológica, p.73, 2003.

GOMES, Nilma Lino. Limites e possibilidades da implementação da lei n.10.639/03 no contexto das políticas públicas em educação. In: PAULA, Marilene de.; HERINGER, Rosana (orgs). Caminhos convergentes: estado e sociedade na superação das desigualdades raciais no Brasil. Rio de Janeiro: Fundação Heringer Boll/ActionAid, 2009.

GOMES, Nilma Lino. Um olhar além das fronteiras: educação e relações raciais. Belo Horizonte: autêntica, 2007.

LUCKESI, Cipriano. O educador: quem é ele. São Paulo: Educatio, 2005.

MORRETO, Vasco Pedro. Planejamento: planejando a educação para o desenvolvimento de competências. Petrópolis, Rio de Janeiro: Vozes, 2007.

ORGANIZAÇÃO DAS NAÇÕES UNIDAS- UNESCO. Declaração de Durban de 2001 (III Conferência Mundial contra o Racismo, a Discriminação Racial, a Xenofobia e formas Conexas de Intolerância). Disponível em: http://unesdoc.unesco.org. Acesso em 15 de agosto de 2018.

QUIJANO, Aníbal. Colonialidade do poder, eurocentrismo e América Latina. A colonialidade do saber: eurocentrismo e ciências sociais. Perspectivas latino-americanas. Buenos Aires: CLACSO, 233, 2005.

SILVEIRA, Sergio Roberto. O corpo na religiosidade africana e na cultura religiosa afrobrasileira: implicações na formação do professor, in DAXENBERGER, Ana Cristina Silva e SÁ SOBRINHO, Rosivaldo Gomes. A diversidade com estudos dos princípios étnicos. Editora UFPB: João Pessoa, 2013.

UNITED NATIONS EDUCATIONAL SCIENTIFC AND CULTURAL ORGANAZATION UNESCO. Declaração Universal Sobre a Diversidade Cultural. 2002. Disponível em: http://unesdoc.unesco.org/images/0012/001271/127160por.pdf. Acesso em: 15 de agosto de 2018. 
VIDEIRA, Piedade Lino. Dança do marabaixo: cultura negra em busca da memória afroamapaense. In: CUNHA JR., Henrique Antunes; GOMES, Ana Beatriz Sousa (orgs.). Educação e afrodescendência no Brasil. Fortaleza: Edições UFC, 2008.

Recebido em: 05/01/2022

Aprovado em: 08/02/2022

Publicado em: 12/02/2022 